\section{Transplantation and Cellular Therapy}

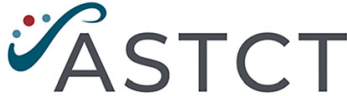

American Society for

Transplantation and Cellular Therapy

\title{
Systematic Reviews in Hematopoietic Cell Transplantation and Cellular Therapy: Considerations and Guidance from the American Society for Transplantation and Cellular Therapy, European Society for Blood and Marrow Transplantation, and Center for International Blood and Marrow Transplant Research Late Effects and Quality of Life Working Committee
}

\author{
Akshay Sharma ${ }^{1, \#}$, Sherif M. Badawy ${ }^{2,3, \#}$, Elizabeth M. Suelzer ${ }^{4}$, Hemant S. Murthy $^{5}$, Pinki Prasad ${ }^{6}$, \\ Hesham Eissa ${ }^{7}$, Paul A. Carpenter ${ }^{8}$, Mehdi Hamadani ${ }^{9}$, Myriam Labopin ${ }^{10}$, Hélène Schoemans ${ }^{11}$, \\ André Tichelli ${ }^{12}$, Rachel Phelan ${ }^{13}$, Betty K. Hamilton ${ }^{14}$, David Buchbinder ${ }^{15}$, Annie Im $^{16}$, \\ Rebecca Hunter $^{17}$, Ruta Brazauskas ${ }^{18}$, Linda J. Burns ${ }^{19, *}$ \\ ${ }^{1}$ Department of Bone Marrow Transplantation and Cellular Therapy, St. Jude Children's Research Hospital, Memphis, Tennessee \\ ${ }^{2}$ Department of Pediatrics, Northwestern University Feinberg School of Medicine, Chicago, Illinois \\ ${ }^{3}$ Division of Hematology, Oncology and Stem Cell Transplant, Ann E Robert H. Lurie Children's Hospital of Chicago, Chicago, Illinois \\ ${ }^{4}$ Medical College of Wisconsin, Milwaukee, Wisconsin \\ ${ }^{5}$ Division of Hematology/Oncology, Mayo Clinic Florida, Jacksonville, Florida \\ ${ }^{6}$ Division of Pediatric Hematology/Oncology, Louisiana State University Health Sciences Center/Children's Hospital of New Orleans, New Orleans, Louisiana \\ ${ }^{7}$ Department of Pediatrics, University of Colorado School of Medicine, Blood and Marrow Transplant and Cellular Therapy Program, Center for Cancer and Blood Disorders, \\ Children's Hospital Colorado, Aurora, Colorado \\ ${ }^{8}$ Fred Hutchinson Cancer Research Center and Department of Pediatrics, University of Washington, Seattle, Washington \\ ${ }^{9}$ BMT and Cellular Therapy Program, Department of Medicine, Medical College of Wisconsin and Center for International Blood and Marrow Transplant Research, Milwaukee, \\ Wisconsin \\ ${ }^{10}$ EBMT Paris Study Office, Department of Haematology, Saint Antoine Hospital; INSERM UMR 938, Sorbonne University, Paris, France \\ ${ }^{11}$ Department of Hematology, University Hospitals Leuven, KU Leuven, Leuven, Belgium \\ ${ }^{12}$ Division of Hematology, University Hospital Basel, Basel, Switzerland \\ ${ }^{13}$ Division of Hematology and Oncology, and BMT, Department of Pediatrics, Medical College of Wisconsin and Center for International Blood and Marrow Transplant \\ Research, Milwaukee, Wisconsin \\ ${ }^{14}$ Blood E'Marrow Transplant Program, Department of Hematology and Medical Oncology, Cleveland Clinic Taussig Cancer Institute, Cleveland, Ohio \\ ${ }^{15}$ Division of Pediatric Hematology, Children's Hospital of Orange County, Orange, California \\ ${ }^{16}$ UPMC Hillman Cancer Center, University of Pittsburgh, Pittsburgh, Pennsylvania \\ ${ }^{17}$ Division of Hematology, University of Colorado Anschutz Medical Center, Aurora, Colorado \\ ${ }^{18}$ Division of Biostatistics, Medical College of Wisconsin and Center for International Blood and Marrow Transplant Research, Milwaukee, Wisconsin \\ ${ }^{19}$ Center for International Blood and Marrow Transplant Research, Milwaukee, Wisconsin
}

Article history:

Received 2 December 2020

Accepted 2 December 2020

\section{Key Words:}

Systematic reviews

Hematopoietic cell

transplantation

Cellular therapy

\begin{abstract}
A B S T R A C T
Systematic reviews apply rigorous methodologies to address a prespecified, clearly formulated clinical research question. The conclusion that results is often cited to more robustly inform decision making by clinicians, thirdparty payers, and managed care organizations about the clinical question of interest. Although systematic reviews provide a rigorous standard, they may be infeasible when the task is to create general disease-focused guidelines comprising multiple clinical practice questions versus a single major clinical practice question. Collaborating transplantation and cellular therapy society committees also recognize that the quantity and or quality of reference sources may be insufficient for a meaningful systematic review. As the conduct of systematic reviews has evolved over time in terms of grading systems, reporting requirements, and use of technology, here we provide
\end{abstract}

This article is co-published in the journals Transplantation and Cellular Therapy and Bone Marrow Transplantation https://doi.org/10.1016/j.jtct.2020.12.002 or https://doi.org/10.1038/s41409-020-01199-1.

Financial disclosure: See Acknowledgments on page XXX.

*Correspondence and reprint requests: Linda J. Burns, MD, Consultant and Sr. Scientific Director, Center for International Blood and Marrow Transplant Research-

Milwaukee, 9200 W Wisconsin Ave, Suite C5500, Milwaukee, WI 53226.

E-mail address: lburns@mcw.edu (L.J. Burns).

\# Akshay Sharma and Sherif M. Badawy, contributed equally to this work. 
current guidance on methodologies, resources for reviewers, and approaches to overcome challenges in conducting systematic reviews in transplantation and cellular therapy.

(c) 2020 The American Society for Transplantation and Cellular Therapy and Springer Nature. Published by Elsevier Inc. All rights reserved.

\section{INTRODUCTION}

Reviews based on a systematic assessment of evidence from the literature help providers make informed clinical decisions and educate third-party payers and managed care organizations about best practices [1,2]. These evidence-based, or systematic reviews, include an a priori stated research question, a well-described comprehensive literature search, a justification for the inclusion or exclusion of the available evidence based on independent reviewers, a risk of bias assessment, an appraisal of the quality of collected data, and a systematic presentation and synthesis of the findings of included studies [3-8]. If the quality of evidence permits, a quantitative analysis (meta-analysis) also may be performed [9]. This systematic approach minimizes individual bias and increases the reliability and quality of the conclusions drawn [8], making systematic reviews the gold standard in evidence-based medicine [10].

In 1999, the American Society for Blood and Marrow Transplantation (ASBMT; now the American Society for Transplantation and Cellular Therapy [ASTCT]) launched an initiative to conduct reviews of the role of transplantation in select diseases [1]. In 2000, the Evidence-Based Review Steering Committee published the methodology to be followed, with inclusion criteria to be determined by the expert panel, the quality of the body of evidence to be graded based according to Shipp et al. [11], and the strength of recommendations to be graded according to Chalmers et al. [12]. The methodology was revised in 2005 to incorporate 4 standard inclusion/exclusion criteria. Studies had to be published in 1990 or later, to have a minimum of $70 \%$ of subjects with the disease under review or results stratified by the disease, and to have 25 or more subjects, unless exclusion of such studies would profoundly affect treatment recommendations; moreover, meeting abstracts and data from non-peer-reviewed journals were to be excluded [13]. The Scottish Intercollegiate Guidelines Network guidelines were to be used to assess the levels of evidence and to grade the strength of treatment recommendations; methodology for conducting a meta-analysis was included [13,14]. As of 2009, 7 reviews had been published [15-21], at which time the Steering Committee recommended that reviews be updated at 5-year intervals [22].

Many systematic reviews have been performed by ASTCT, the European Society for Blood and Marrow Transplantation (EBMT), the Center for International Blood and Marrow Transplantation Research (CIBMTR), the National Institutes of Health $(\mathrm{NIH})$, other professional societies, and investigators worldwide on transplantation and cellular therapy (TCT)related topics using various methodologies. For example, more than 50 systematic reviews and meta-analyses were published between January 1, 2018, and July 31, 2020 (MeSH terms: "hematopoietic stem cell transplantation" AND "systematic review" AND "meta-analysis"; MEDLINE search and review independently conducted by A.S. and L.J.B.).

Since the 2005 ASBMT statement, the conduct of systematic reviews has evolved with the use of new grading systems, adoption of uniform reporting requirements, and development of software programs that facilitate international collaborative reviews. Here we review how the current standards for conducting systematic reviews apply to the field of TCT, provide useful resources for professionals undertaking such reviews, and give guidance on how to overcome common pitfalls along with some practical considerations.

\section{CONDUCT OF A SYSTEMATIC REVIEW}

Suggested steps for conducting the review are shown in Figure 1 with details provided in the following sections. Examples of software and websites that can assist throughout these steps are provided in Table 1.

\section{Form a multidisciplinary team}

Before beginning the review process, a multidisciplinary study team should be assembled based on the intended purpose and target audience. Expertise in data search and information retrieval, the clinical topic, and knowledge synthesis methods should be represented in this team. A library information sciences specialist is an asset to facilitate design of a comprehensive search strategy and enable retrieval of all relevant studies across different databases. Specific expertise in biostatistics should be included if quantitative data synthesis is planned. Ideally, stakeholders linked to the research topic (eg, clinicians, patients, caregivers, donors, policy makers), should be included to enhance the use of review findings [6,23-25]; their inclusion may be mandated by some funding bodies [26]. All team members should disclose relevant conflicts of interest and professional or intellectual biases to critically appraise their potential contribution to the team.

\section{Determine the question and inclusion/exclusion criteria}

A clear, concise, specific, and answerable research question is critical in developing a high-quality review. In preparation to question development, the team should first evaluate research that has been conducted previously or is ongoing, noting findings relevant to the target audience $[27,28]$. It may be optimal to update a previous review if there have been considerable advances in the literature or methodological advances [29-34].

A common acronym used to refine research questions is PICOS: Population or problem of interest; Intervention,

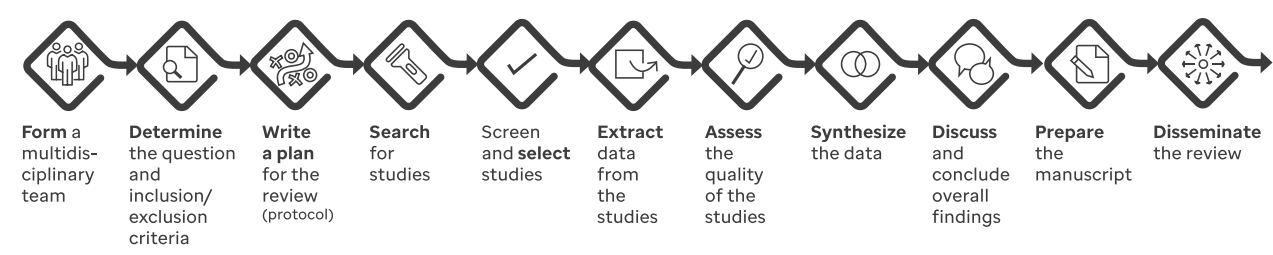

Figure 1. Flow diagram of the various steps involved in developing a systematic review. 
Table 1

Examples of software and websites that can assist in developing and managing a systematic review

\begin{tabular}{|c|c|c|c|c|c|c|c|}
\hline \multirow[t]{2}{*}{ Product } & \multirow[t]{2}{*}{ Cost } & \multicolumn{6}{|c|}{ Functionality } \\
\hline & & $\begin{array}{l}\text { Citation } \\
\text { manager }\end{array}$ & Deduplication & $\begin{array}{l}\text { Screening } \\
\text { studies }\end{array}$ & $\begin{array}{l}\text { Documentation } \\
\text { of review }\end{array}$ & $\begin{array}{l}\text { Data } \\
\text { xtraction }\end{array}$ & $\begin{array}{l}\text { Statistical } \\
\text { analysis }\end{array}$ \\
\hline $\begin{array}{l}\text { Abstrackr http://abstrackr.cebm. } \\
\text { brown.edu }\end{array}$ & Free & & & $x$ & & & \\
\hline CADIMA https://www.cadima.info & Free & & $x$ & $x$ & $\times$ & & \\
\hline $\begin{array}{l}\text { Colandr https://www.colandrapp. } \\
\text { com }\end{array}$ & Free & & & $x$ & $x$ & $x$ & \\
\hline $\begin{array}{l}\text { Covidence https://www.covidence. } \\
\text { org }\end{array}$ & $\begin{array}{l}\text { Free limited version. } \\
\text { Full version requires } \\
\text { subscription. }\end{array}$ & & & $x$ & $x$ & $x$ & \\
\hline $\begin{array}{l}\text { DistillerSR https://www.evidence } \\
\text { partners.com/products/distillersr-sys } \\
\text { tematic-review-software/ }\end{array}$ & $\begin{array}{l}\text { Subscription } \\
\text { required }\end{array}$ & & $x$ & $x$ & $x$ & $x$ & \\
\hline EndNote https://endnote.com & $\begin{array}{l}\text { Free online version } \\
\text { lacks some function- } \\
\text { ality. Desktop ver- } \\
\text { sion requires } \\
\text { subscription. }\end{array}$ & $x$ & $x$ & $x$ & & & \\
\hline $\begin{array}{l}\text { EPPI-Reviewer https://eppi.ioe.ac.uk/ } \\
\text { CMS/Default.aspx?alias=eppi.ioe.ac. } \\
\text { uk/cms/er4\& }\end{array}$ & $\begin{array}{l}\text { Subscription } \\
\text { required }\end{array}$ & $x$ & & $\times$ & $x$ & $x$ & $x$ \\
\hline Rayyan https://rayyan.qcri.org & Free & & & $x$ & $x$ & & \\
\hline $\begin{array}{l}\text { RevMan https://training.cochrane. } \\
\text { org/resource/introduction-revman }\end{array}$ & Free & $x$ & & $x$ & $x$ & & $x$ \\
\hline $\begin{array}{l}\text { Systematic Review Data Repository } \\
\text { (SRDR) https://ser.ahrq.gov }\end{array}$ & Free & & & $x$ & $x$ & $x$ & \\
\hline $\begin{array}{l}\text { System for the Unified Management, } \\
\text { Assessment and Review of Informa- } \\
\text { tion (SUMARI) http://www.jbisu } \\
\text { mari.og }\end{array}$ & $\begin{array}{l}\text { Subscription } \\
\text { required }\end{array}$ & $x$ & & $x$ & $x$ & $x$ & $\times$ \\
\hline Zotero https://www.zotero.org & Free & $\times$ & $\times$ & $\times$ & & & \\
\hline
\end{tabular}

exposure, or indicator to be evaluated; Comparison or control group; Outcome measure being assessed; Study design [25]. All 5 components might not be applicable, but considering each will enable the team to refine the question. In TCT, one can define the study population based on standard characteristics such as (1) demographic data, including participants' age, sex, race, and ethnicity; (2) disease-related factors, such as disease status (eg, in remission or with relapsed or refractory disease) and disease risk (eg, early, intermediate, high, very high) [35-37]; and (3) transplantation and cell therapy-related factors, including type (eg, allogeneic or autologous), donor source (eg, HLA-matched related/unrelated donor or haploidentical donor), graft source (eg, bone marrow, peripheral blood-derived stem cells, or cord blood). Similarly, comparison groups may be broadly (eg, HLA-matched related graft recipients versus HLA-matched unrelated graft recipients) or more specifically defined (eg, transplant recipients receiving calcineurin inhibitor-based graft-versus-host disease [GVHD] prophylaxis versus others).

Study inclusion/exclusion criteria should be defined before initiating the literature search to avoid bias by the available literature. Any necessary revisions based on practical aspects of the available data after the initial search should be applied consistently throughout the review process $[27,28]$. Criteria should state year of study publication, language restrictions (if applicable), and specific items linked to the research question. Accepted study designs that may best answer the research question also should be predefined [38]. Studies may be of varying designs but should be studying the same outcome. Generally, when conducting a systematic review measuring an outcome of an intervention, data from randomized controlled trials (RCTs) and quasi-RCTs are preferred. However, highquality nonrandomized studies and observational studies may be included, because they provide evidence of "real world" data. Case series and case reports are usually excluded because they are associated with a high potential for bias [27], but may be included if the research question is related to a rare event or outcome. Review articles, abstracts, meeting presentations, editorials, viewpoints, and other data that have not undergone peer review are typically excluded.

\section{Write a plan for the review (protocol)}

The plan for the review should be summarized into a protocol guided by consensus recommendations in the Preferred Reporting Items for Systematic Reviews and Meta-Analyses (PRISMA) guidelines [39]. The protocol should include relevant background, rationale for conducting the review, the research question, data collection methods (literature search plan, inclusion and exclusion criteria, and data extraction methods), risk of bias assessment methods, and planned data synthesis and/or analysis methods. The protocol should be published to maintain transparency, prevent duplicate efforts by other investigators, ensure reproducibility, and reduce bias [6]. This can be done through online registration in such databases as PROSPERO [40], Cochrane Library [41], F1000 Research [42], Joanna Briggs Institute [43], Open Science Framework registries [44], or Zenodo [45] or published in a peer-reviewed journal. Any protocol amendments should be recorded. An example of such a protocol recently initiated as a collaborative effort between the CIBMTR and the EBMT is available in the PROSPERO database (registration no. CRD42020147640) [46]. 


\section{Search for studies}

As bibliographic databases differ with respect to their coverage of scholarly disciplines, publication types, dates of publication, journals and books indexed, geographic locations, languages, and search syntaxes, it is a best practice to use more than one database [47]. In addition to the commonly used MEDLINE database, other medical databases include Embase, Web of Science, Scopus, Cumulative Index to Nursing and Allied Health Literature (CINAHL), PsycINFO, and Cochrane Library. Most databases require subscriptions; access may be available through academic libraries.

The search strategies should be constructed in collaboration with a library information sciences specialist to ensure that they are well-constructed, thorough, and reproducible [27]. The team should identify keywords, name variations, synonyms, and subject headings for the key concepts of the research question. Researchers from different institutions, fields of discipline, or geographic locations may use different terminology to describe the same idea; therefore, the search strategy should be as inclusive as possible. For instance, hematopoietic stem cell transplantation may be referred to as HSCT, hematopoietic cell transplantation, bone marrow transplantation, stem cell transplantation, cord blood transplantation, or peripheral blood transplantation. Terms are joined using Boolean operators (AND, OR, NOT). An example of a search strategy in TCT is included as Supplementary Table S1. Search strategies also should be adjusted using the advanced search features specific to the database searched and peer reviewed to ensure quality [48]. The search strategy should be pilot tested to ensure that the major articles considered relevant are being captured. If key articles are missing, the search string should be modified and retested before finalization.

\section{Screen and select studies}

Specialized software applications have simplified the process of screening, removing duplications, and selecting studies (Table 1). All references should undergo screening in 2 stages by at least 2 independent members of the study team $[6,25]$. The first stage involves screening the title and abstract to exclude articles that clearly do not meet the inclusion criteria. In the second stage, the full text of all potentially eligible articles is reviewed to ensure that the studies meet all inclusion and exclusion criteria. If there are unresolved disagreements, a discussion with a third reviewer may help reach a consensus. For studies chosen for inclusion, the reference list of each article and/or any publications referring to that study can be hand-searched for further relevant studies (the "snowball method"). The study flow and the reasons for excluding full-text papers should be documented in an adapted PRISMA flow diagram; a hypothetical example diagram is shown in Figure 2 [49,50].

\section{Extract data from the studies}

The use of a standardized data collection form ensures the uniformity of data acquisition. Piloting the form will ensure that all relevant data are collected and adjustments are made to avoid unnecessary details. Free-text fields should be limited and data coded in predefined numerical, fixed-text (yes/no), or drop-down menus or lists to avoid discrepancies and

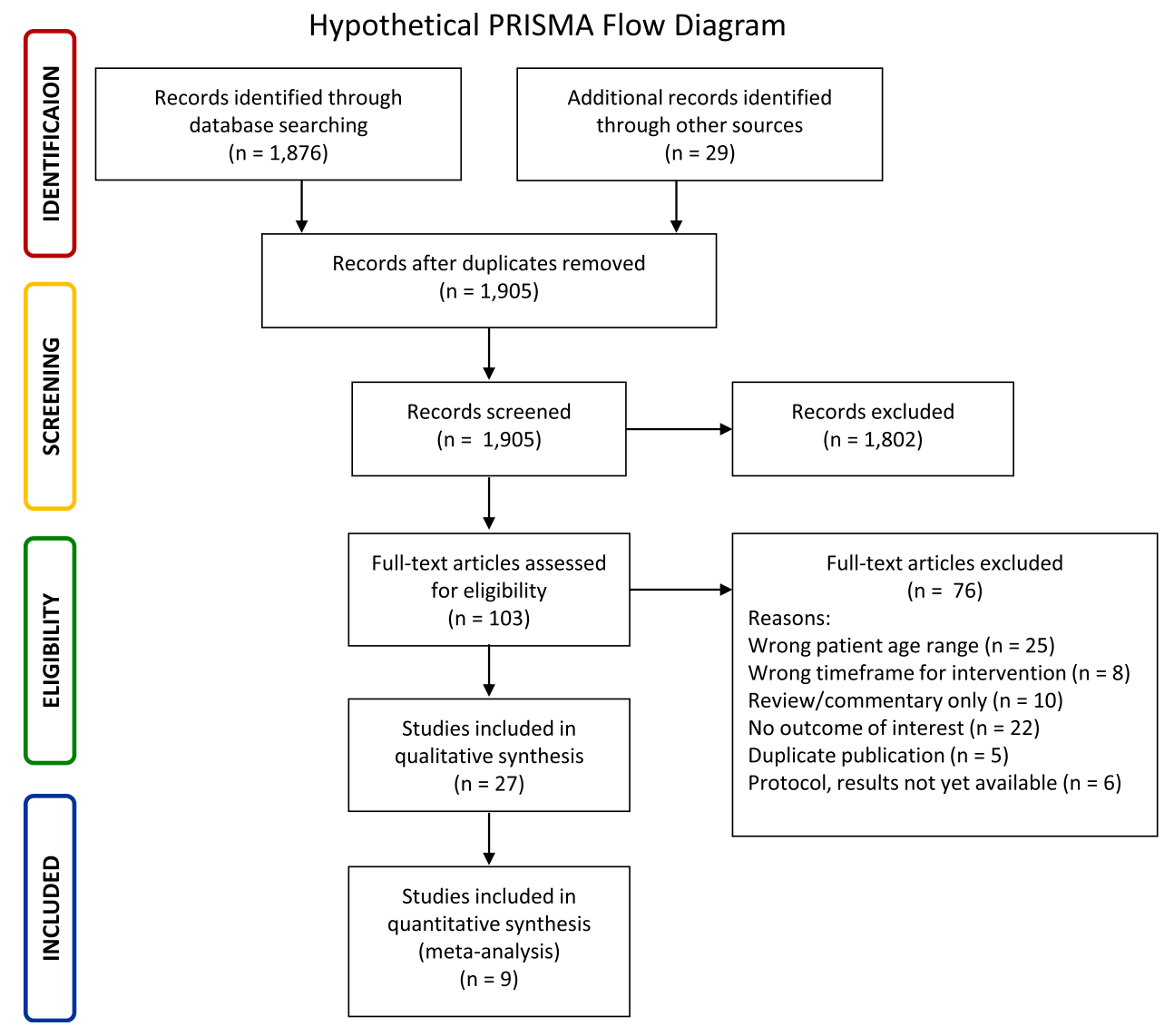

Figure 2. Hypothetical PRISMA flow diagram. 
ambiguity at the time of data synthesis. Software applications are available that support the creation of custom data collection forms (Table 1); although word-processing and spreadsheet software programs also may be used. A minimum of 2 independent reviewers should collect data from all included studies. The level of interrater agreement may be calculated using the $\kappa$ statistic and reported [51]. Any disagreements should be resolved by discussion with a third reviewer.

\section{Assess the quality of the studies}

The quality of evidence and risk of bias of the included studies should be evaluated. Table 2 provides the quality ratings and their definitions of several frameworks that have been used in TCT reviews depending on the scope and research question. More than 100 global organizations have adopted the Grading of Recommendations Assessment, Development and Evaluation (GRADE) [52-54] framework for evaluating the quality of a body of evidence [55]. The GRADE framework has 4 levels of quality; various factors may impact the quality levels [56]. Factors decreasing the quality of a review include inadequate design of included studies, lack of direct evidence, unexplained heterogeneity or inconsistency of results, lack of precision of results, and publication bias (ie, when the outcome influences the decision to publish). Inclusion of several large studies or studies reporting a large magnitude of effect or dose-response gradient in a review increase the quality of the evidence. The quality rating may decrease or increase by 1 level for each factor up to a maximum of 3 levels. Therefore, the GRADE framework addresses a common challenge reviewers face when assessing the quality of evidence from a wide range of studies with heterogeneity in design, populations, interventions, and/or outcomes. Although the quality of evidence from case reports and case series is very low, this evidence may be incorporated in decision making based on the GRADE approach when no other higher-level evidence is available $[56,57]$.

Several tools are available for evaluating the risk of bias within a study and across studies. The Cochrane risk-of-bias tool may be used for RCTs [58,59], ROBINS-I for nonrandomized studies of interventions [60], and the Newcastle-Ottawa Scale for observational studies [61-63]. Case reports and small case series cannot be assessed for risk of bias.

\section{Synthesize the data}

All systematic reviews include a systematic presentation and synthesis of the findings from the studies. Software programs that facilitate the synthesis of data are listed in Table 1. Developing a table with similar information for each study may identify patterns and lead to further thematic clustering of studies and tabulation of data [64]. Calculating the frequency of different types of results and/or outcomes is another way to create an initial description of the pattern of the included studies, but it does not take into account the sample size, precision level, or size of the effect $[65,66]$.

If the quality of evidence permits, a quantitative synthesis of the data (meta-analysis) may be performed to more accurately evaluate effect size [9]. A meta-analysis combines results of separate RCTs or other high-quality studies using statistical methods [67]. Weighted study effect sizes are used to give greater weight to studies with higher precision [68]. Results are usually presented in the form of a forest plot (example shown in Supplementary Figure S1), which not only provides an overview of individual studies, but also shows the degree to which they are statistically heterogeneous [69]. If there is a statistical heterogeneity among the included studies, a subgroup analysis may be explored [70]. Funnel plots are

Table 2

Frameworks for Assessing Quality of Evidence

\begin{tabular}{|c|c|c|}
\hline Framework & Quality rating & Definition \\
\hline \multirow[t]{3}{*}{ AHRQ [72] } & Good & Design and conduct of study addresses risk of bias with appropriate measurement of outcomes and analytic methods \\
\hline & Fair & Do not meet criteria for good quality, no flaw likely to cause major bias, missing information often drives rating \\
\hline & Poor & Inappropriate design, conduct, analysis, or reporting \\
\hline \multirow[t]{3}{*}{ GRADE [52-54] } & High & Randomized trials; or double-upgraded observational studies. \\
\hline & Moderate & Downgraded randomized trials; or upgraded observational studies. \\
\hline & Low & Double-downgraded randomized trials; or observational studies. \\
\hline \multirow[t]{3}{*}{ NCCN [73] } & High & \multirow{3}{*}{$\begin{array}{l}\text { Based upon factors of quality (eg, trial design and how the results/observations were derives), quantity of data (eg, } \\
\text { number of trials, size of trials, clinical observations only), and consistency of data (eg, similar or conflicting results across } \\
\text { available studies of observations), }\end{array}$} \\
\hline & Lower & \\
\hline & Any & \\
\hline \multirow[t]{7}{*}{ SIGN [14] } & $1++$ & High-quality meta-analyses, systematic reviews of RCTs, or RCTs with a very low risk of bias \\
\hline & $1+$ & Well-conducted meta-analyses, systematic reviews of RCTs, or RCTs with a low risk of bias \\
\hline & $2++$ & $\begin{array}{l}\text { High-quality systematic reviews of case-control or cohort studies; high-quality case-control or cohort studies with a } \\
\text { very low risk of confound, bias, or chance and a high probability that the relationship is causal. }\end{array}$ \\
\hline & $2+$ & $\begin{array}{l}\text { Well-conducted case-control or cohort studies with a low risk of confounding, bias, or chance and a moderate probabil- } \\
\text { ity that the relationship is causal. }\end{array}$ \\
\hline & $2-$ & $\begin{array}{l}\text { Case-control or cohort studies with a high risk of confounding, bias, or chance and a significant risk that the relationship } \\
\text { is not causal }\end{array}$ \\
\hline & 3 & Nonanalytic studies, eg, case reports of case series \\
\hline & 4 & Expert opinion \\
\hline \multirow[t]{3}{*}{ USPHS/IDSA [74] } & $\mathrm{I}$ & Evidence from $\geq 1$ properly randomized, controlled trial. \\
\hline & II & $\begin{array}{l}\text { Evidence for } \geq 1 \text { well-designed clinical trial without randomization, from cohort or case-controlled analytic studies } \\
\text { (preferable from }>1 \text { center), or from multiple time series or dramatic results from uncontrolled experiments. }\end{array}$ \\
\hline & III & Evidence from opinions of respected authorities based on clinical experience, descriptive. \\
\hline
\end{tabular}

AHRQ indicates Agency for Healthcare Research and Quality; NCCN, National Comprehensive Cancer Network; SIGN, Scottish Intercollegiate Guidelines Network; USPHS/IDSA, United States Public Health Service and Infectious Disease Society of America. 
frequently used to detect potential publication bias where studies with negative results or no statistically significant findings are less likely to be published in peer-reviewed journals (example shown in Supplementary Figure S2).

Including only randomized or quasi-randomized studies in a systematic review may be possible for a well-studied topic [71]. However, it still may be appropriate to perform a meta-analysis with few RCTs [59] and/or retrospective cohort studies if the quality of the studies is high [63]. However, pooling data from poor-quality studies into a meta-analysis is not recommended, because errors and biases from individual studies will be compounded, yielding misleading results and conclusions.

\section{Discuss and conclude overall findings}

Team member discussion is critical to reach valid conclusions and, if relevant, establish the strength of recommendation for an intervention. Multiple frameworks have been used in TCT reviews for assessing the strength of a recommendation (Table 3). GRADE is frequently used $[54,55]$, but other frameworks for assessing the strength of recommendations may be considered based on the focus and scope of the review [14,72-74].

Factors affecting the strength of a recommendation in GRADE include the quality of the evidence, uncertainty about the balance between desirable and undesirable effects, uncertainty or variability in patient values and preferences, and uncertainty about whether the intervention represents a wide use of resources. Strong recommendations suggest that all or almost all individuals would choose that intervention, and thus it might not be necessary to present several therapeutic options to patients. Weak recommendations imply that there is likely to be important variation in the decision that informed individuals are likely to make, and that engaging patients and families in a shared decision making process is essential. Recommendations are more likely to be weak rather than strong when the quality of evidence is low, when evidence suggests that desirable and undesirable consequences are closely balanced [56], when there is substantial variation or uncertainty in patient values and preferences, and when interventions require considerable resources.

\section{Prepare the manuscript}

The PRISMA statement includes a 27-item checklist that covers the steps of a systematic review and meta-analysis that should be included with reviews submitted for peer review [75]. Other specialized guidelines and checklists that may be used depending on the review include ENhancing Transparency in REporting the synthesis of Qualitative research (ENTREQ) [76], Meta-Analysis Reporting Standards (MARS) [77], and Meta-analysis Of Observational Studies in Epidemiology (MOOSE) [78].

\section{Disseminate the review to enhance uptake of findings}

The effective dissemination of study findings has a significant impact on how evidence-based findings are incorporated

Table 3

Frameworks for Assessing Strength of Recommendations

\begin{tabular}{|c|c|c|}
\hline Framework & Strength & Definition \\
\hline \multirow[t]{4}{*}{ AHRQ [72] } & High & $\begin{array}{l}\text { We are very confident that the estimate of effect lies close to the true effect for this outcome. The body of evidence has } \\
\text { few or no deficiencies. }\end{array}$ \\
\hline & Moderate & $\begin{array}{l}\text { We are moderately confident that the estimate of effect lies close to the true effect for this outcome. The body of evi- } \\
\text { dence has some deficiencies. }\end{array}$ \\
\hline & Low & $\begin{array}{l}\text { We have limited confidence that the estimate of effect lies close to the true effect for this outcome. The body of evidence } \\
\text { has major or numerous deficiencies (or both). }\end{array}$ \\
\hline & Insufficient & $\begin{array}{l}\text { We have no evidence, we are unable to estimate an effect, or we have not confidence in the estimate of effect for this } \\
\text { outcome. No evidence is available, or the body of evidence has unacceptable deficiencies, precluding reaching a } \\
\text { conclusion. }\end{array}$ \\
\hline \multirow[t]{2}{*}{ GRADE [52-54] } & Strong & When the desirable effects of an intervention clearly outweigh the undesirable effects, or clearly do not \\
\hline & Weak & $\begin{array}{l}\text { When the trade-offs are less certain - either because of low quality evidence or because evidence suggests that desirable } \\
\text { and undesirable effects are closely balanced }\end{array}$ \\
\hline \multirow[t]{3}{*}{ NCCN [73] } & 1 & Based on high-level of evidence, there is uniform NCCN consensus that the intervention is appropriate \\
\hline & $2 \mathrm{~A}$ & Based on lower level of evidence, there is uniform NCCN consensus that the intervention is appropriate \\
\hline & $\mathrm{C}$ & Based on high-level of evidence, there is major NCCN disagreement that the intervention is appropriate \\
\hline \multirow[t]{4}{*}{ SIGN [14] } & A & $\begin{array}{l}\text { At least } 1 \text { meta-analysis, systematic review, or RCT rated as } 1++ \text { and directly applicable to the target population or a sys- } \\
\text { tematic review of RCTs or a body of evidence consisting principally of studies rated as } 1+\text {, directly applicable to the tar- } \\
\text { get population, and demonstrating overall consistency of results }\end{array}$ \\
\hline & B & $\begin{array}{l}\text { A body of evidence including studies rates as } 2++ \text {, directly applicable to the target population, and demonstrating overall } \\
\text { consistency of results of extrapolated evidence from studies rated as } 1++ \text { or } 1+\end{array}$ \\
\hline & C & $\begin{array}{l}\text { Body of evidence including studies rated as } 2+\text {, directly applicable to the target populations, and demonstrating overall } \\
\text { consistence of results or extrapolated evidence from studies rated as } 2++\end{array}$ \\
\hline & $\mathrm{D}$ & Evidence level 3 or 4 or extrapolated evidence from studies rated as $2+$. \\
\hline \multirow[t]{4}{*}{ USPHS/IDSA [74] } & A & Should always be offered. \\
\hline & $\mathrm{B}$ & Should generally be offered. \\
\hline & C & $\begin{array}{l}\text { Evidence for efficacy is insufficient to support a recommendation for or against, or evidence for efficacy might not out- } \\
\text { weigh adverse consequences, or cost of the approach. Optional }\end{array}$ \\
\hline & $\mathrm{D}$ & $\begin{array}{l}\text { Moderate evidence for lack of efficacy or for adverse outcome supports a recommendation against use. Should generally } \\
\text { not be offered. }\end{array}$ \\
\hline
\end{tabular}


into clinical practice $[79,80]$. The study team should develop a plan early in the process for dissemination of their findings including, but not limited to, publication in a peer-reviewed journal. Once published, additional aspects of the dissemination plan should be executed, including presentations at conferences, promotion on social media, and distributing the findings in an appropriate format to all other relevant stakeholders, such as policy makers, payers, professional organizations, patients/caregivers and advocates, and hospital administrators. Dissemination of findings can be enhanced by ensuring that multidisciplinary stakeholders are involved from the beginning.

\section{APPROACHES TO SYSTEMATIC REVIEWS WHEN THERE IS A LACK OF HIGH-QUALITY EVIDENCE}

The study team may consider alternative approaches when the amount or quality of evidence is too low to form conclusions. Scoping reviews are a valid method of summarizing the literature when the literature on a particular topic is very scarce or when reviewers want to address a broad research question $[81,82]$. This type of review entails the same searching process as a systematic review but does not require a formal evaluation of the quality of studies and risk of bias assessment.

Clinical questions regarding recently introduced therapeutic approaches may be addressed (eg, clinical practice recommendations for chimeric antigen receptor $\mathrm{T}$ cell therapy) $[83,84]$ or the literature summarized to serve as a basis for future research (eg, conditioning intensity in obese patients) [85]. Another option is to avoid a full formal systematic review but use the modified Delphi method for determining the degree of consensus among experts [86], which may then be combined with a grading system for assigning a strength of the recommendation [87-92].

\section{CONCLUSIONS}

Systematic reviews are critical pieces of medical literature that summarize the totality of evidence to enable sound clinical and policy decisions and identify avenues for future research when applied to a single clinical research question of interest. Transparency of methods throughout their conduct enables reproducibility and a critical assessment of the results by and for all stakeholders. The best practices in methodologic frameworks reviewed here serve as a basis for conducting of high-quality systematic reviews and meta-analyses in TCT and should be updated as they evolve. The use of evidence-based recommendations, informed by rigorous systematic reviews, can be a powerful approach to improve patients' health outcomes.

\section{ACIKNOWLEDGMENTS}

The authors thank Keith A. Laycock, PhD, ELS, for scientific editing and Matthew J. Page, PhD for their critical review of the manuscript.

Financial disclosure: The National Heart, Lung, and Blood Institute (NHLBI) of the National Institutes of Health supported this publication under Award Number K23HL150232 (S.B.). Research funding was also received from Novartis for an investigator-initiated study and consultancy (2020; H.S.). None of the other authors has a financial disclosure to make. The CIBMTR is supported primarily by Public Health Service U24CA076518 from the National Cancer Institute $(\mathrm{NCI})$, the NHLBI, and the National Institute of Allergy and Infectious Diseases (NIAID); U24HL138660 from NHLBI and NCI; OT3HL147741, R21HL140314 and U01HL128568 from the
NHLBI; HHSH250201700006C, SC1MC31881-01-00 and HHSH250201700007C from the Health Resources and Services Administration (HRSA); and N00014-18-1-2850, N00014-181-2888, and N00014-20-1-2705 from the Office of Naval Research; Additional federal support is provided by P01CA111412, R01CA152108, R01CA215134, R01CA218285, R01CA231141, R01AI128775, R01HL129472, R01HL130388, R01HL131731, U01AI069197, U01AI126612, and BARDA. The views expressed in this article do not reflect the official policy or position of the NIH, the Department of the Navy, the Department of Defense, HRSA, or any other agency of the United States Government.

Conflict of interest statement: A.S. is the recipient of an American Society of Scholar Award and serves as a paid consultant for Spotlight Therapeutics and CRISPR Therapeutics/ Vertex Pharmaceuticals and Novartis. Between 2017 and 2020, H.S. participated in advisory boards for Incyte (2018) and Janssen and Novartis (2020). She has received speaker's fees from Jazz Pharmaceuticals (2017), Novartis and Incyte (2018), and Incyte, Jazz Pharmaceuticals, and Takeda (2019) and has received travel grants from EBMT (2017); EBMT, Celgene, and Abbvie (2018); EBMT and Incyte (2019); and EBMT and Gilead (2020).

Authorship statement: A.S. and S.M.B. contributed equally to this work. A.S. wrote the first draft of the manuscript. S.B. and L.J.B. critically reviewed and wrote several sections. All authors provided input, reviewed the final manuscript, and approved the content.

\section{SUPPLEMENTARY MATERIALS}

Supplementary material associated with this article can be found in the online version at doi:10.1016/j.jtct.2020.12.002.

\section{REFERENCES}

1. Evidence-based reviews and the role of blood and marrow transplantation in the treatment of selected disease: an ASBMT policy statement. American Society for Blood and Marrow Transplantation. Biol Blood Marrow Transplant. 2000;6:523.

2. Jones R, Horowitz M, Wall D, et al. ASBMT policy statement regarding the methodology of evidence-based reviews in evaluating the role of blood and marrow transplantation in the treatment of selected diseases. American Society for Blood and Marrow Transplantation. Biol Blood Marrow Transplant. 2000;6:524-525.

3. Schmidt LM, Gotzsche PC. Of mites and men: reference bias in narrative review articles: a systematic review. J Fam Pract. 2005;54:334-338.

4. Cook DJ, Mulrow CD, Haynes RB. Systematic reviews: synthesis of best evidence for clinical decisions. Ann Intern Med. 1997;126:376-380.

5. Petticrew M. Systematic reviews from astronomy to zoology: myths and misconceptions. BMJ. 2001;322:98-101.

6. Garritty C, Stevens A, Hamel C, Golfam M, Hutton B, Wolfe D. Knowledge synthesis in evidence-based medicine. Semin Nucl Med. 2019;49:136-144.

7. Sargeant JM, O'Connor AM. Introduction to systematic reviews in animal agriculture and veterinary medicine. Zoonoses Public Health. 2014;61 (suppl 1):3-9.

8. Grant MJ, Booth A. A typology of reviews: an analysis of 14 review types and associated methodologies. Health Info Libr J. 2009;26:91-108.

9. Hedges LV, Olkin I. Statistical Methods for Meta-Analysis. San Diego, CA: Academic Press; 1985.

10. OCEBM Levels of Evidence Working Group. The Oxford 2011 Levels of Evidence 2. Oxford Centre for Evidence-Based Medicine. Available at: https:// www.cebm.ox.ac.uk/resources/levels-of-evidence/ocebm-levels-of-evi dence. Accessed August 13, 2020.

11. Shipp MA, Abeloff MD, Antman KH, et al. International Consensus Conference on High-Dose Therapy with Hematopoietic Stem Cell Transplantation in Aggressive Non-Hodgkin's Lymphomas: report of the jury. J Clin Oncol. 1999; 17:423-429.

12. Chalmers TC, Berrier J, Sacks HS, Levin H, Reitman D, Nagalingam R. Metaanalysis of clinical trials as a scientific discipline. II: Replicate variability and comparison of studies that agree and disagree. Stat Med. 1987;6:733744.

13. Jones R, Nieto Y, Rizzo JD, et al. The evolution of the evidence-based review: evaluating the science enhances the art of medicine-statement of the Steering Committee for Evidence-Based Reviews of the American 
Society for Blood and Marrow Transplantation. Biol Blood Marrow Transplant. 2005;11:819-822.

14. Harbour R, Miller J. A new system for grading recommendations in evidence-based guidelines. BMJ. 2001;323:334-336.

15. Hahn T, Wolff SN, Czuczman M, et al. The role of cytotoxic therapy with hematopoietic stem cell transplantation in the therapy of diffuse large cell B-cell non-Hodgkin's lymphoma: an evidence-based review. Biol Blood Marrow Transplant. 2001;7:308-331.

16. Hahn T, Wingard JR, Anderson KC, et al. The role of cytotoxic therapy with hematopoietic stem cell transplantation in the therapy of multiple myeloma: an evidence-based review. Biol Blood Marrow Transplant. 2003;9:437.

17. Hahn T, Wall D, Camitta B, et al. The role of cytotoxic therapy with hematopoietic stem cell transplantation in the therapy of acute lymphoblastic leukemia in children: an evidence-based review. Biol Blood Marrow Transplant. 2005;11:823-861.

18. Hahn T, Wall D, Camitta B, et al. The role of cytotoxic therapy with hematopoietic stem cell transplantation in the therapy of acute lymphoblastic leukemia in adults: an evidence-based review. Biol Blood Marrow Transplant. 2006:12:1-30.

19. Oliansky DM, Rizzo JD, Aplan PD, et al. The role of cytotoxic therapy with hematopoietic stem cell transplantation in the therapy of acute myeloid leukemia in children: an evidence-based review. Biol Blood Marrow Transplant. 2007;13:1-25

20. Oliansky DM, Appelbaum F, Cassileth PA, et al. The role of cytotoxic therapy with hematopoietic stem cell transplantation in the therapy of acute myelogenous leukemia in adults: an evidence-based review. Biol Blood Marrow Transplant. 2008; 14:137-180

21. Oliansky DM, Antin JH, Bennett JM, et al. The role of cytotoxic therapy with hematopoietic stem cell transplantation in the therapy of myelodysplastic syndromes: an evidence-based review. Biol Blood Marrow Transplant. 2009;15:137-172.

22. Jones RB, Nieto Y, Wall D, et al. Methodology for updating published evidence-based reviews evaluating the role of blood and marrow transplantation in the treatment of selected diseases: a policy statement by the American Society for Blood and Marrow Transplantation. Biol Blood Marrow Transplant. 2009;15:761-762.

23. Grimshaw JM, Thomas RE, MacLennan G, et al. Effectiveness and efficiency of guideline dissemination and implementation strategies. Health Technol Assess. 2004;8:1-72. iii-iv.

24. Lumley J, Chamberlain C, Dowswell T, Oliver S, Oakley L, Watson L. Interventions for promoting smoking cessation during pregnancy. Cochrane Database Syst Rev. 2009;3: CD001055.

25. University of York NHS Centre for Reviews and Dissemination. Systematic Reviews: CRD's Guidance for Undertaking Reviews in Health Care. York, UK: Centre for Reviews and Dissemination, University of York; 2009.

26. Graham ID, Tetroe J, Gagnon M. Lost in translation: just lost or beginning to find our way? Ann Emerg Med. 2009;54:313-314. discussion 314.

27. Institute of Medicine (US) Committee on Standards for Systematic Reviews of Comparative Effectiveness Research. In: Eden J, Levit L, Berg A Morton S, eds. Finding What Works in Health Care: Standards for Systematic Reviews. Washington, DC: National Academies Press; 2011.

28. Thomas J, Kneale D, McKenzie JE, Brennan SE, Bhaumik S. Chapter 2: Determining the scope of the review and the questions it will address. In: Higgins JPT, Thomas J, Chandler J, et al., eds. Cochrane Handbook for Systematic Reviews of Interventions. version 6.1. Available at: www.training. cochrane.org/handbook. Accessed December 1, 2020.

29. Oliansky DM, Larson RA, Weisdorf D, et al. The role of cytotoxic therapy with hematopoietic stem cell transplantation in the treatment of adult acute lymphoblastic leukemia: update of the 2006 evidence-based review. Biol Blood Marrow Transplant. 2012;18:18-36.e6.

30. Oliansky DM, Camitta B, Gaynon P, et al. Role of cytotoxic therapy with hematopoietic stem cell transplantation in the treatment of pediatric acute lymphoblastic leukemia: update of the 2005 evidence-based review. Biol Blood Marrow Transplant. 2012;18:505-522.

31. Shah N, Callander N, Ganguly S, et al. Hematopoietic stem cell transplantation for multiple myeloma: guidelines from the American Society for Blood and Marrow Transplantation. Biol Blood Marrow Transplant. 2015;21:1155-1166

32. Oliansky DM, Czuczman M, Fisher RI, et al. The role of cytotoxic therapy with hematopoietic stem cell transplantation in the treatment of diffuse large B cell lymphoma: update of the 2001 evidence-based review. Biol Blood Marrow Transplant. 2011;17:20-47.

33. DeFilipp Z, Advani AS, Bachanova V, et al. Hematopoietic cell transplantation in the treatment of adult acute lymphoblastic leukemia: updated 2019 evidence-based review from the American Society of Transplantation and Cellular Therapy. Biol Blood Marrow Transplant. 2019;25:21132123.

34. Dholaria B, Savani BN, Hamilton BK, et al. Hematopoietic cell transplantation in the treatment of newly disgnosed adult acute myeloid leukemia: an evidence-based review from the American Society of Transplantation and Cellular Therapy [e-pub ahead of print]. Biol Blood Marrow Transplant. doi: 10.1016/j.bbmt.2020.09.020, Accessed October 19, 2020.
35. Sorror M, Storer B, Sandmaier BM, et al. Hematopoietic cell transplantation-comorbidity index and Karnofsky performance status are independent predictors of morbidity and mortality after allogeneic nonmyeloablative hematopoietic cell transplantation. Cancer. 2008;112:1992-2001.

36. Sorror ML, Sandmaier BM, Storer BE, et al. Comorbidity and disease statusbased risk stratification of outcomes among patients with acute myeloid leukemia or myelodysplasia receiving allogeneic hematopoietic cell transplantation. J Clin Oncol. 2007;25:4246-4254.

37. Armand P, Kim HT, Logan BR, et al. Validation and refinement of the Disease Risk Index for allogeneic stem cell transplantation. Blood. 2014;123:3664-3671.

38. McKenzie JE, Brennan SE, Ryan RE, Thomson HJ, Johnston RV, Thomas J. Chapter 3: Defining the criteria for including studies and how that will be grouped for synthesis. In: Higgins JPT, Thomas J, Chandler J, et al., eds. Cochrane Handbook for Systematic Reviews of Interventions.version 6.1. Available at: www.training.cochrane.org/handbook. Accessed December $1,2020$.

39. Moher D, Shamseer L, Clarke M, et al. Preferred reporting items for systematic review and meta-analysis protocols (PRIMSA-P) 2015 statement. Syst Rev. 2015;4:1.

40. National Institute for Health Research (NIHR). PROSPERO: International prospective register of systematic reviews. Available at: https://www.crd. york.ac.uk/prospero/. Accessed August 13, 2020.

41. Cochrane Library. Available at: https://www.cochranelibrary.com/. Accessed August 13, 2020.

42. F1000 Research. Available at: https://f1000research.com/. Accessed August 13, 2020.

43. Joanna Briggs Institute. Available at: https://joannabriggs.org/. Accessed August 13, 2020.

44. OSF registries. Available at: https://osf.io/registries. Accessed August 13, 2020.

45. Zenodo. Available at: https://zenodo.org/. Accessed August 13, 2020.

46. Sharma A, Badawy S, Suelzer E, et al. Male-specific late effects after hematopoietic cell transplantation.2020. Available at: https://www.crd.york.ac.uk/ prospero.Record:147640. Accessed August 13, 2020.

47. Wu YP, Aylward BS, Roberts MC, Evans SC. Searching the scientific literature: implications for quantitative and qualitative reviews. Clin Psychol Rev. 2012;32:553-557.

48. Sampson M, McGowan J, Cogo E, Grimshaw J, Moher D, Lefebvre C. An evidence-based practice guideline for the peer review of electronic search strategies. J Clin Epidemiol. 2009;62:944-952.

49. Moher D, Liberati A, Tetzlaff J, Altman DG, PRISMA Group. Preferred reporting items for systematic reviews and meta-analyses: the PRISMA statement. BMJ. 2009;339:b2535.

50. Liberati A, Altman DG, Tetzlaff J, et al. The PRISMA statement for reporting systematic reviews and meta-analyses of studies that evaluate healthcare interventions: explanation and elaboration. BMJ. 2009;339:b2700.

51. Altman DG. Measuring agreement. In: Altman DG, ed. Practical Statistics for Medical Research. London, UK: CRC Press; 1991.

52. Guyatt G, Oxman AD, Akl EA, et al. GRADE guidelines: 1. IntroductionGRADE evidence profiles and summary of findings tables. J Clin Epidemiol. 2011;64:383-394.

53. Guyatt GH, Oxman AD, Schünemann HJ, Tugwell P, Knottnerus A. GRADE guidelines: a new series of articles in the Journal of Clinical Epidemiology.J Clin Epidemiol. 2011;64:380-382.

54. Guyatt GH, Oxman AD, Vist GE, et al. GRADE: an emerging consensus on rating quality of evidence and strength of recommendations. BMJ. 2008;336:924-926

55. Alonso-Coello P, Schünemann HJ, Moberg J, et al. GRADE Evidence to Decision (EtD) frameworks: a systematic and transparent approach to making well informed healthcare choices. 1: Introduction. BMJ. 2016;353:i2016.

56. Guyatt GH, Oxman AD, Kunz R, et al. What is "quality of evidence" and why is it important to clinicians? BMJ. 2008;336:995-998.

57. Murad MH, Sultan S, Haffar S, Bazerbachi F. Methodological quality and synthesis of case series and case reports. BMJ Evid Based Med. 2018;23:60-63.

58. Sterne JAC, Savovic J, Page MJ, et al. RoB 2: a revised tool for assessing risk of bias in randomized trials. BMJ. 2019;366:I44898.

59. Rashidi A, Meybodi MA, Cao W, et al. Myeloablative versus reduced-intensity hematopoietic cell transplantation in myelodysplastic syndromes: systematic review and meta-analysis. Biol Blood Marrow Transplant. 2020;26:e138-e141.

60. Sterne JA, Hernán MA, Reeves BC, et al. ROBINS-I: a tool for assessing risk of bias in non-randomised studies of interventions. BMJ. 2016;355:i4919.

61. Wells GA, Shea B, O'Connell D, et al. The Newcastle-Ottawa Scale (NOS) for Assessing the Quality of Nonrandomised Studies in Meta-Analyses. Ottawa, ON, Canada: Ottawa Hospital Research Institute; 2014.

62. Aulakh S, Reljic T, Yassine F, et al. Allogeneic hematopoietic cell transplantation is an effective treatment for patients with Richter syndrome: a systematic review and meta-analysis [e-pub ahead of print]. Hematol Oncol Stem Cell Ther. doi:10.1016/j.hemonc.2020.05.002, Accessed December 1, 2020 . 
63. Parrondo RD, Reljic T, Iqbal M, et al. Efficacy of autologous and allogeneic hematopoietic cell transplantation in Waldenström macroglobulinemia: a systematic review and meta-analysis. Clin Lymphoma Myeloma Leuk. 2020;20:e694-e711.

64. Popay J, Roberts H, Sowden A, et al. Guidance on the conduct of narrative synthesis in systematic reviews. A Product from the ESRC Methods Programme. version 1. April 2006.

65. Bushman BJ, Wang MC. Vote-counting methods in meta-analysis. In: Cooper HM, Hedges LV, Valentine JC, eds. Handbook of Research Synthesis. 2nd ed. New York, NY: Russell Sage Foundation; 2009:207-220.

66. Cwikel J, Behar L, Rabson-Hare J. A comparison of a vote count and a metaanalysis review of intervention research with adult cancer patients. Res Soc Work Pract. 2000;10:139-158.

67. Lipsey MW, Wilson DB. Practical Meta-Analysis. Washington, DC: Sage Publications; 2001.

68. Verbeek J, Ruotsalainen J, Hoving JL. Synthesizing study results in a systematic review. Scand J Work Environ Health. 2012;38:282-290.

69. Anzures-Cabrera J, Higgins JPT. Graphical displays for meta-analysis: an overview with suggestions for practice. Res Synth Methods. 2010;1:66-80.

70. Glasziou PP, Sanders SL. Investigating causes of heterogeneity in systematic reviews. Stat Med. 2002;21:1503-1511.

71. Lehrnbecher T, Fisher BT, Phillips B, et al. Guideline for antibacterial prophylaxis administration in pediatric cancer and hematopoietic stem cell transplantation. Clin Infect Dis. 2020;71:226-236.

72. Berkman ND, Lohr KN, Ansari MT, et al. Grading the strength of a body of evidence when assessing health care interventions: an EPC update. J Clin Epidemiol. 2015;68:1312-1324.

73. National Comprehensive Cancer Network. Development and update of the NCCN guidelines.Available at: https://www.nccn.org/professionals/develop ment.aspx. Accessed August 13, 2020.

74. 1999 USPHS/IDSA guidelines for the prevention of opportunistic infections in persons infected with human immunodeficiency virus. U.S. Public Health Service (USPHS) and Infectious Diseases Society of America (IDSA). MMWR Recomm Rep. 1999;48:61-66. 1-59,.

75. Page M, McKenzie J, Bossuyt P, et al. The PRISMA 2020 statement: an updated guideline for reporting systematic reviews.Available at: https://osf. io/preprints/metaarxiv/v7gm2. Accessed October 18, 2020.

76. Tong A, Flemming K, McInnes E, Oliver S, Craig J. Enhancing transparency in reporting the synthesis of qualitative research: ENTREQ. BMC Med Res Methodol. 2012;12:181.

77. APA Publications and Communications Board Working Group on Journal Article Reporting Standards. Reporting standards for research in psychology: why do we need them? What might they be? Am Psychol. 2008;63:839-851.

78. Stroup DF, Berlin JA, Morton SC, et al. Meta-analysis of observational studies in epidemiology: a proposal for reporting. Meta-analysis Of Observational Studies in Epidemiology (MOOSE) group. JAMA. 2000;283:2008-2012.

79. Grol R, Grimshaw J. From best evidence to best practice: effective implementation of change in patients' care. Lancet. 2003;362:1225-1230.

80. Khera N. From evidence to clinical practice in blood and marrow transplantation. Blood Rev. 2015;29:351-357.
81. Munn Z, Peters M, Stern C, Tufanaru C, McArthur A, Aromataris E. Systematic review or scoping review? Guidance for authors when choosing between a systematic or scoping review approach. BMC Med Res Methodol. 2018; $18: 143$

82. Tricco AC, Lillie E, Zarin W, et al. PRISMA extension for scoping reviews (PRISMA-ScR): checklist and explanation. Ann Intern Med. 2018;169:467473.

83. Jain T, Bar M, Kansagra AJ, et al. Use of chimeric antigen receptor T cell therapy in clinical practice for relapsed/refractory aggressive B cell nonHodgkin lymphoma: an expert panel opinion from the American Society for Transplantation and Cellular Therapy. Biol Blood Marrow Transplant. 2019;25:2305-2321.

84. Kansagra AJ, Frey NV, Bar M, et al. Clinical utilization of chimeric antigen receptor T-cells (CAR-T) in B-cell acute lymphoblastic leukemia (ALL)-an expert opinion from the European Society for Blood and Marrow Transplantation (EBMT) and the American Society for Blood and Marrow Transplantation (ASBMT). Bone Marrow Transplant. 2019;54:1868-1880.

85. Bubalo J, Carpenter PA, Majhail N, et al. Conditioning chemotherapy dose adjustment in obese patients: a review and position statement by the American Society for Blood and Marrow Transplantation practice guideline committee. Biol Blood Marrow Transplant. 2014;20:600-616.

86. McMillan SS, King M, Tully MP. How to use the nominal group and Delphi techniques. Int J Clin Pharm. 2016;38:655-662.

87. Montoto S, Corradini P, Dreyling M, et al. Indications for hematopoietic stem cell transplantation in patients with follicular lymphoma: a consensus project of the EBMT-Lymphoma Working Party. Haematologica. 2013;98:1014-1021.

88. Kröger NM, Deeg JH, Olavarria E, et al. Indication and management of allogeneic stem cell transplantation in primary myelofibrosis: a consensus process by an EBMT/ELN international working group. Leukemia. 2015;29:2126-2133.

89. Kharfan-Dabaja MA, Kumar A, Hamadani M, et al. Clinical practice recommendations for use of allogeneic hematopoietic cell transplantation in chronic lymphocytic leukemia on behalf of the Guidelines Committee of the American Society for Blood and Marrow Transplantation. Biol Blood Marrow Transplant. 2016:22:2117-2125.

90. Kharfan-Dabaja MA, Kumar A, Ayala E, et al. Clinical practice recommendations on indication and timing of hematopoietic cell transplantation in mature $\mathrm{T}$ cell and NK/T cell lymphomas: an international collaborative effort on behalf of the Guidelines Committee of the American Society for Blood and Marrow Transplantation. Biol Blood Marrow Transplant. 2017;23:1826-1838.

91. Kanate AS, Kumar A, Dreger P, et al. Maintenance therapies for Hodgkin and non-Hodgkin lymphomas after autologous transplantation: a consensus project of ASBMT, CIBMTR, and the Lymphoma Working Party of EBMT. JAMA Oncol. 2019;5:715-722.

92. Penack O, Marchetti M, Ruutu T, et al. Prophylaxis and management of graft-versus-host disease after stem cell transplantation for haematological malignancies: updated consensus recommendations of the European Society for Blood and Marrow Transplantation. Lancet Haematol. 2020;7: e157-e167. 